\title{
浅析网络教学的意义及其利弊
}

\author{
武懿 \\ 哈尔滨市呼兰区利民中学校
}

DOI:10.32629/er.v3i5.2774

[摘 要] 当今社会, 网络已经融入人们生活的方方面面。由于经济和科技的大力发展,网络技术极大地方便了人们的出行、工作以及生活。对 于学校教学而言, 当然也少不了网络的 “助攻”。网络教学从原来的辅助教学手段逐渐转变成主流教学模式, 不仅打破了授课时间和空间的限制, 而且能在必要时 “挺身而出”, 为教育教学提供便利。因此, 网络教学具有极大的意义和必要性。本文对于网络教学的意义, 以及随之而产生的 一系列利弊进行了简要分析。

[关键词] 网络教学; 意义; 优点; 弊端

信息化时代的来临使得网络技术飞速发展, 随着社会经济和科学技 术的蓬勃发展, 现代化教学设施和学习设备均得到不断完善。在学校硬 件教学设施及家庭学习软件设备不断普及的背景下, 网络教学成为大势 所趋。相较于传统的师生面对面授课的学校教学模式, 网络教学具有灵活 性、多样性、方便快捷等众多优点, 因此, 曾经作为辅助教学手段的网络教 学翻身 “当家作主”, 逐渐成为主流教学模式。网络教学的举措意义重大, 然而, 在其为学生的教育提供便利的同时, 也带来了诸多困扰。

\section{1 网络教学的意义和必要性}

为了响应国家新课程改革的政策, 上至各大高校, 下至中小学、幼儿园, 各个学校都积极开展了网络授课。为了全方位开展工作和学习, 丰富学校 的教学形式, 提高教育教学质量, 提升学生学习兴趣以及学生综合素质, 网 络成了重要的载体和媒介。因此, 网络教学这一举动具有重大意义和自身 的必要性。

\section{1 社会意义}

网络教学具有重大的社会意义。首先, 网络时代的来临使得人们之间 的联系变得更加紧密, 正所谓 “牵一发而动全身”, 在举国上下各行各业都 采取网络化办公的背景下, 学校更不能独善其身, 而是要搭乘网络时代的 快车, 大力开展网络教学。为了尽可能增加个人经济来源, 越来越多的人开 始利用互联网办公。互联网作为相互沟通和协助办公的依靠和重要保证, 不仅成就了众多微商、网红和各大购物网站, 也成就了众多利用互联网办 公的企业、单位和团体组织。学校作为重要的人才培养和输送的社会公共 机构组织, 为了使全国近千万大中小学生能随时随地尽享网络教育资源带 来的便利, 更需要网络作为后盾来辅助和开展教育教学活动。因此, 网络教 学具有极大的社会意义。

\section{2 个人意义}

孩子是祖国的花朵, 也是祖国的未来。学生的教育问题从始至终都是 重中之重。每逢节假日和寒暑假, 就有众多学生因为脱离学校和老师的监 督而放松自我。随着学生年龄的增加和青春期逆反心理的影响, 家长在监 管孩子过程中的地位和力度逐渐降低, 因此越来越多的学生整天沉迷于网 络、虚度光阴。这种情况持续几天就已经足够让家长崩溃, 如果不及时遏 止, 而是让孩子越陷越深, 无法自拔, 最后终将酿成悲剧, 后果不堪设想。但 反过来, 如果让孩子每天利用网络在线上学习, 通过网络听课、培养个人爱 好, 而不是上网、打游戏, 那结果将会截然相反。知识会积少成多, 孩子也 会逐渐养成自主学习的好习惯。因此, 网络教学对于个人、尤其对于学生 自身也具有重要意义。

1.3 必要性

基于网络教学的社会意义和个人意义, 国家有必要开展网络授课。这
样不仅可以给学生提供更为丰富的教育资源、充实学生的课余生活, 还能 够在应激情况下正常开展教学活动。而对于学生来说, 不论年龄大小, 都需 要网络课程来充实自己, 更需要来自网络教学的约束和监督。

\section{2 网络教学的优势}

网络时代的来临使得距离不再是问题, 即使相隔甚远也能实现 “面对 面的沟通”。搭乘信息技术快车, 承蒙时代关怀, 学校教学不仅能够在授课 形式上有所突破, 授课内容也会更加丰富多彩。网络教学具有如下优势:

2. 1 教学不受时空限制

网络教学相较于传统的面授形式最大的优势在于它不受时间和空间 的影响和限制。无论何时何地, 只要有网络, 就能实现授课。随着科技的发 展, 音频视频软件和设备层出不穷, 网络授课也能使师生实现隔空 “面对 面” 交流问答。因此, 授课时间和地点可以灵活安排。同时, 也为师生省去 了赶到指定上课地点的交通时间。

\section{2 资源丰富且共享}

网络为教学提供了交流的平台, 老师们不仅可以在网络上搜索到自己 所需的备课资料, 丰富自己的课堂内容, 也可以观看其他教师、特别是名师 的课程, 这些课程可以为教师本身提供新的教学思路、拓宽视野, 从而提高 授课技能。此外, 还可以通过网络分享自己的课程和资源, 为其他需要资源 的老师提供便利, 让分享互惠互利。同时, 及时的分享上课内容也能为学生 提供复习的资料及依据, 课上没听懂的孩子可以重复学习, 没跟上的孩子 可以重新整理笔记, 对于程度较高的学生来说则可以进行知识的二次吸收 和内化, 温故而知新。

2. 3 提高教师授课能力和水平

传统的教学方式中, 教师主要依靠黑板进行板书教学, 多媒体网络教 学只是教学的辅助。而随着时代的发展, 网络教学逐渐成为主流形式。这 就对教师的网络教学技术应用水平提出了新的要求和挑战。由于某些学科 的特殊性, 需要 “听说” 兼备, 而网络教学恰好能提供众多视听资源。因此 市、区教育局以及学校多次组织教师进行网络软件授课技术的培训, 教师 个人也根据实际需要进行了所应用软件的研究和探索。这些无不推动着教 师授课水平的进步和授课质量的提高。从前死气沉沉的课堂因网络技术而 变得生气勃勃, 学生学习兴趣也随之大大提高, 听课注意力也更为集中。此 为双赢。

\section{3 网络教学的弊端}

万物皆有利弊, 网络也是一把双刃剑。师生在享受网络教学带来的便 利与好处的同时, 也面临着一系列随之而产生问题。这些弊端无时无刻不 影响着学生听课效果和质量, 亟待解决。

3.1网络硬软件设施、技术不完备 
网络授课最常发生的同样也是教师最担心的状况就是网络不稳定。 具体体现在以下几个方面: 第一, 上课前或中途突然断网。教师担心不 能如期上线, 耽误课程进度, 让众多孩子辛苦等待; 学生则担心错过重点 内容, 中途进入导致跟不上进度, 且担心被记为迟到或缺席。各学科知识 连贯性均比较大, 一旦断网极易造成学生跟不, 导致后续知识听不懂或 夹生。第二, 上课途中互动不能快速连线。课堂时间有限, 尤其是网络课 程, 为了保护学生视力上课时间不宜过长, 这就使得原本紧张的授课时 间更加紧张。为了保证听课质量对学生连线提问必不可少, 如果网络出 现卡顿, 则会增加等待时间, 更有可能由于网络不顺畅导致一些学生不 能参与互动, 这些都会使课堂教学效率大打折扣。网络化授课因师生存 在距离, 不能对学生的听课状态实时监控, 需要学生互动才能检验其掌 握与否, 如缺少互动, 教学效果则会大打折扣。此外, 有些家境困难的学 生不能提供满足上网课需求的硬件设备, 这将会直接影响听课质量, 耽 误学生学习。这种情况下网络授课会给其家庭带来经济负担, 同时也会 在一定程度上给孩子带来心理压力。

\section{2 学生方面}

活泼好动是学生的普遍特点, 无论年龄大小。尤其是正直青春期的孩 子, 自制力差, 需要家长和老师给予适当的监督和正确的引导。传统的学校 教育使学生时刻都在老师的监管范围之中, 学生的行为会受到很大的约 束。但网络教学则不同, 教师鞭长莫及, 越来越多的孩子因为无人监督而不 认真听课、不按时完成作业。甚至和老师及家长斗智斗勇, 只登陆挂机, 但人却不在电子设备旁听课, 或切出听课界面做其他的事情……这种现象 随着越来越多的家长降低监督力度和线上教学时间的延长而越发严重。这 种行为如果不能及时遏止, 后果将不堪设想。对于任何学科而言, 学生若缺 课均会导致知识断档, 更何况长期不听课? 此外, 网络授课给学生带来的 最直接的负面影响就是用眼过渡。青少年的眼部结构还没有发育完全, 用 眼时间过长会导致近视等眼部疾病。而电子设备屏幕产生的蓝光等会加大 对学生眼睛的刺激。经历过疫情期间的网课, 越来越多的学生会近视, 而本 身就近视的学生则会加重近视程度。这些对学生造成的影响都是无法逆转 和挽回的。

3. 3教师方面

首先, 传统的教学方法是教师通过板书呈现课堂重点, 供学生理清 思路和记录。通过黑板呈现重难点可以使知识具有逻辑性, 学生对新知
识的学习也有据可依。网络教学虽大大减少了板书内容, 但需借助某些 软件和工具才能完成。而这些工具虽能够进行书写但不太容易操作, 如 书写不自如导致字写得很难看, 或者笔速很慢、耽误时间等。其次, 作业 批改也变得困难起来。学生完成作业后教师不能及时批改, 对于学生的 错误之处不能及时指出, 对于学生共性的问题也无法准确把握。这些都 为之后的教学埋下了 “隐患”, 因为教师只有足够了解学生才能更好的 安排教学内容。

\section{4 结语}

信息时代的来临既是机遇也是挑战。作为人民教师, 要抓住这个机遇 并接受网络时代带来的教学方面的挑战。经历了这场考验后, 每位教师的 网络教学技能都会大大提高, 这对今后的学校教学只有百利而无一害。网 络教学既是时代的要求, 也是教育的需求。作为教育人, 我们要走在时代的 前沿, 用先进的教学思想武装自己, 用科学的教育手段和方法灌溉祖国的 花朵。

\section{[参考文献]}

$[1]$ 戴晋.网络教学平台在高职英语教育应用中的利弊研究 [J].福建茶 叶,2020(03):154.

[2]范卉清.别让直播授课落下寒门学子 [J].新闻 - 评论,2020(07):006.

[3] 郭丽佳. 新型冠状病毒肺炎疫情期间网络授课存在的问题及解决 措施[J].中国现代教育装备,2020(3):11-12.

[4]孙孝荣.在线网络教育平台对传统学校授课的影响及对策[J].中华 少年,2017(24):273-274.

[5]薛礼,凌江川.疫情期间“停课不停学”网络教学有效策略思考[J]. 中国多媒体与网络教学学报,2020(2):188-189.

[6] 尹岳. 高中英语网络授课利弊及方法初探[ J]. 科学导报 - 学 术,2020(9):67-68.

[7]张谷子,姚希明,刘雪梅.浅析中华文化英文课程网络授课的意义与 优势[J].才智,2018(8):137.

[8]张勇.多媒体网络环境下的高中英语阅读课教学模式探索[J]. 课程 教育研究,2019(41):104-105.

\section{作者简介:}

武懿(1992--), 女, 汉族, 黑龙江哈尔滨人, 硕士研究生, 研究方向: 英 语教学。 